Journal of Animal and Veterinary Advances 10 (1): 121-127, 2011

ISSN: $1680-5593$

(C) Medwell Journals, 2011

\title{
Multivariate Discrimination among Three Trachurus Species from Turkey
}

\author{
Hakan Karaoglu and Ali Osman Belduz \\ Department of Biology, Faculty of Arts and Sciences, \\ Karadeniz Technical University, 61080 Trabzon, Turkey
}

\begin{abstract}
Trachurus mediterraneus (Steindachner, 1868), T. trachurus (Linnaeus, 1758) and T. picturatus (Bowdich, 1825) are three closely related, morphologically similar horse mackerel species. Here multivariate analyses are used to study interspecific morphometric and meristic variation for these three species. The statistical analysis confirmed that three species were well differentiated. In particular, discriminant analysis revealed that a strong discriminating power of the morphometric variables and three Trachurus species was clearly distinguished due to measurements of preanal length, head length, eye diameter, length of lateral line and numbers of scale in lateral line.
\end{abstract}

Key words: Trachurus species, carangidae, morphology, multivariate analysis, Turkey

\section{INTRODUCTION}

The horse mackerel ranges widely throughout the tropical waters throughout temperate, tropical and subtropical waters of the world (Eschmeyer, 2003). The genus Trachurus which was first described its taxonomies by Nichols (1920) this genus is represented by three species: the Atlantic horse mackerel, T. trachurus (L.), the Mediterranean horse mackerel, T. mediterraneus (Steind.) and the blue jack mackerel, T. picturatus (Bowd.) in the Turkey waters. Multivariate analysis of morphometric and meristic characters is a standard tool for defining population units and differentiating between genera, species, sub-species and groups of animals (Fridriksson, 1958; Thorpe, 1976; Boetius, 1980; Pierce et al., 1994; Tudela, 1999).

A recently published study has pointed morphological variation within rather than among species: Murta (2000), morphometric and meristic characters analyzed for stock identification of Atlantic horse mackerel T. trachurus; Turan (2004) studied morphologic differentiation among stocks of Mediterranean horse mackerel, T. mediterraneus throughout the Black, Marmara, Aegean and Northeastern Mediterranean seas from coasts of the Turkish waters; Belduz and Bektas (2009) were studied for T. trachurus populations from Turkey by multivariate analyses but the morphological differences among Trachurus species were not analyzed. Moreover, genetic relationships among Trachurus sp. from Turkey have mainly been examined by mtDNA genes (Bektas and Belduz, 2008) and they were suggested that genetic distances among $T$. mediterraneus and $T$. picturatus are more closely related to each other more than any of T. trachurus.

The goal of the present research are to reveal interspecies variation in morphological and meristic characters of three Trachurus species and to identify the best set of characters for group separation with the use of the multivariate analysis technique.

\section{MATERIALS AND METHODS}

The samples made up of 480 specimens of Trachurus mediterraneus (9.6-19.7 cm SL; $\mathrm{N}=270)$, T. trachurus $(10.7-26.2 \mathrm{~cm}, \mathrm{~N}=150)$ and $T$. picturatus $(19.5-26.5 \mathrm{~cm}$, $\mathrm{N}=60$ ) were collected from nine different locations in the four different seas of Turkey (Aegean sea, Sea of Marmara, Black sea and Northeastern Mediterranean sea) (Fig. 1). All specimens were directly fixed in $20 \%$ formalin. Analysis took place at the Karadeniz Technical University. Particular measurements were always made by the same person to minimise errors.

Measurements and counts were taken from 30 individuals per population, comprising 11 morphometric: Lengths of First Dorsal Fins (DFL1), Second Dorsal (DFL2), Pectoral (PFL), Anal (AL), Lateral Line (LL), Preanal (PrAL) Lengths, maximum Body Heights $(\mathrm{BH})$, minimum Body Heights (CPH), Head Length ( $\mathrm{HL}$ ) and Eye Diameter (ED) and 5 meristic characters: number of branched rays in First Dorsal (DFR1), Second Dorsal (DFR2), Pelvic (PFR), Anal (AFR) and number of pectoral rays $(\mathrm{PFR})$ and number of scales on thelateral line (LS)

Corresponding Author: Ali Osman Belduz, Department of Biology, Faculty of Arts and Sciences, Karadeniz Technical University, 61080 Trabzon, Turkey 


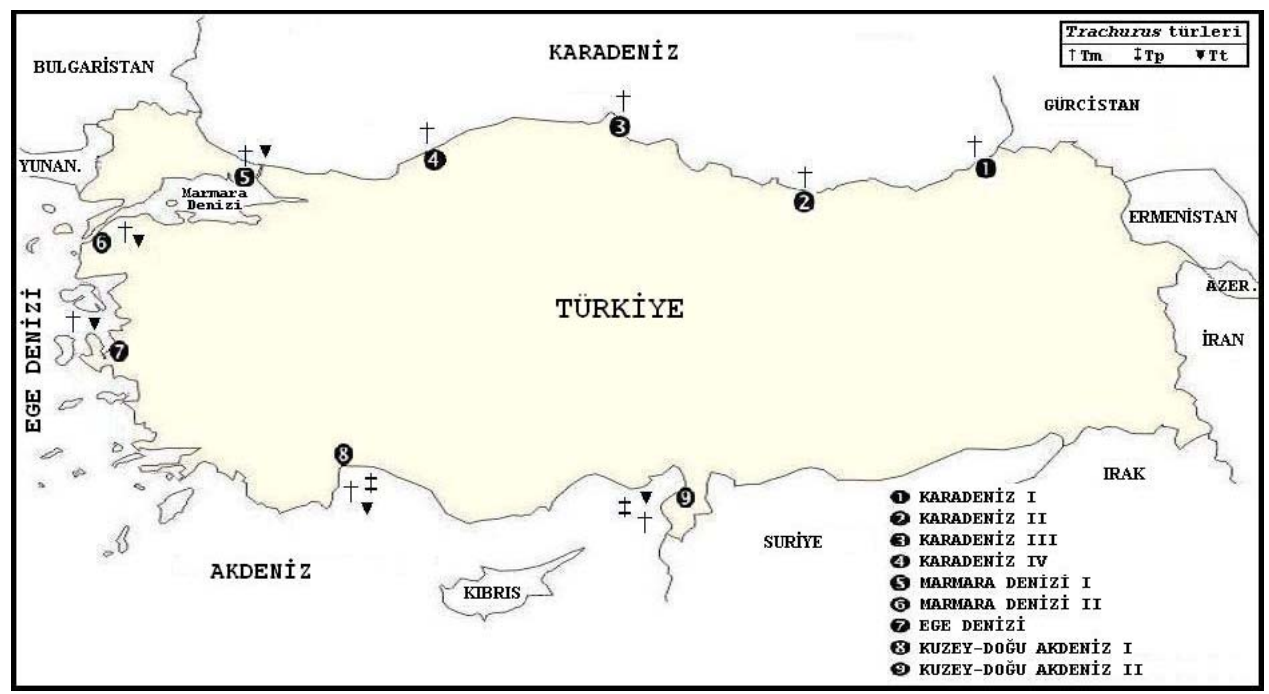

Fig. 1: Map showing the different sampled localities for three species from Turkey

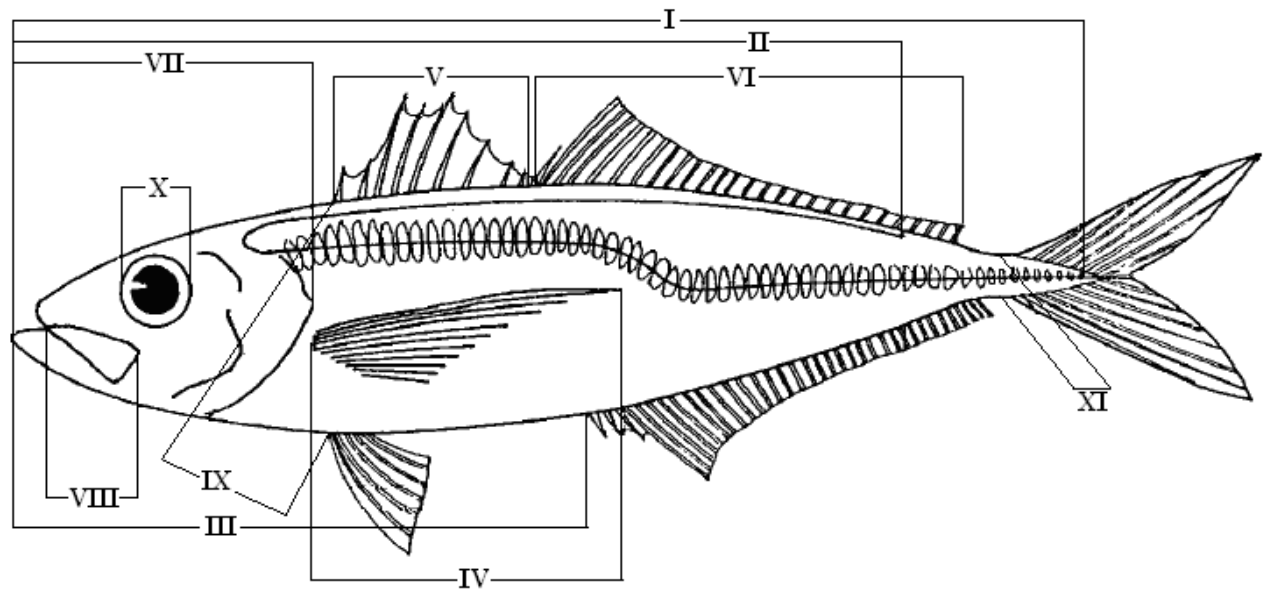

Fig. 2: Measurements on the body of Horse mackerel. I) SL: Standart Length; II) LL: Length of Lateral line; III) PrAL: Preanal Length; IV) PFL: Pectoral Fin Length; V) DFL1: First Dorsal Fin Length; VI) DFL2: Second Dorsal Fin Length; VII) HL: Head Length; VIII) ML: Maxilla Lenght; IX) BD: Body Depth; X) ED: Eye Diameter; XI) CPD: Caudal Peduncle Depth (Murta, 2000)

were selected based on previous research (Murta, 2000) (Fig. 2). The morphometric measurements were measured to the nearest $0.01 \mathrm{~mm}$. Standard length was expressed as a percentage of the total length. Others metric measurements were expressed as percentages of the standard length. Eye Diameter (ED) was expressed as percentages of the head length $(\mathrm{ED} / \mathrm{HL})$ and the minimum body height was expressed as a percentage of the maximum body height (CPD/BD). All variables used for morphometric and meristic analysis were measured under a binocular microscope.

To determine interspecific variations among Trachurus species, morphometric and meristic characters were used separately in multivariate analyses since their allocation abilities are different statistically. Because of the variation in size of fish from different areas, morphometric and meristic data were statistically adjusted to permit comparative analysis in terms of shape and counts independently of size (Thorpe, 1976). Accordingly, comparison of morphometric data among different populations should be preceded by a suitable correction to remove size-effect. Carangid fishes show allometric growth (Santic et al., 2002). All individual morphometric data were thus corrected using the $\mathrm{M}_{\mathrm{S}}=\mathrm{M}\left(\mathrm{L}_{\mathrm{O}} / \mathrm{L}_{\mathrm{s}}\right)^{b}$ equation (Elliott et al., 1995).

The pattern of discrimination between species was examined by canonical discriminant analysis. Discriminant functions for each species were worked out on the basis 
of variables with a higher individual contribution, evaluated from standardized discriminant coefficients. To investigate the phenotypic relationships between populations a dendrogram was constructed based on Mahalanobis distances using UPGMA cluster analysis of arithmetic averages (Sneath and Sokal, 1973). Statistical analyses were carried out using STATISTICA Statsoft, Inc. Version 7.0 packages.

\section{RESULTS AND DISCUSSION}

Derived discriminant functions in DFA using eleven of the size-corrected morphometric characters identified Head Length (HL), Length of Lateral Line (LL), PreAnal Length (PrAL), Body Depth (BD), Eye Diameter (ED) and Pelvic Fine Length (PFL) as significant six contributors that were found to be useful for distinguishing related species. The rest of the morphometrics also contributed significantly to heterogeneity but were not good identifiers of related taxa (Table 1). The Wilks test indicated a significant difference for mean vectors for the eleven distances among $T$. mediterraneus, T. trachurus and $T$. picturatus ( $\mathrm{L}=0.073 ; \mathrm{F}=175.65$; $\mathrm{p}<0.0001$ ) (Table 1). Discriminant analysis results revealed that there are clearly differentiating characteristics between these species, e.g., lateral line scale counts, termination point of dorsal accessory lateral line. $T$. picturatus has been low body depth and differences in the head characters of fish. This demonstrated that the total morphometric variation between species, considering 11 measures could be reduced to just six discriminants. Discriminant analysis based on these standardized variables resulted in $100 \%$ success in classifying fish to the correct species. Despite this high degree of accuracy, it should be taken into account that these results applied to only the length classes analyzed for each species. No precision was shown for classes out of the analyzed range due to allometric changes in shape during growth. The projection of scores for $T$. mediterraneus, $T$. trachurus and $T$. picturatus indicated strong dependence on the first component rather than the second which was probably due to allometry. However, in the present study such influence might have been minimized by the reduction of allometry effects derived from the range of three species sizes which were very similar. It was showed that the three species were morphologically clearly distinct.

The plot of the canonical variables 1 and 2 shows a significant discrimination of species scores in three significant main groups along CV1 (Table 2). As revealed by the respective eigen-values, the first two Canonical Variates (CV) explained 100\% of the variability. This demonstrated that it was proper to use them for morphological analyses, since they adequately explained the variability for the whole set of data (Johnson and Wichern, 1992). The first Canonical Variate (CV1) was responsible for $57.2 \%$ of the variation among-species, the second (CV2) for 43.8\% (Table 2). Examination of the correlations revealed that $\mathrm{PrAL}$ and $\mathrm{HL}$ contributed mostly to CV1 and hence (This first axis was as expected, dominated by the effect of body size), accounted mostly for the variance in the data whereas LS contributed mostly to CV2. These 3 characteristics also showed the highest values of correlation with the first and second canonical

Table 1: Summary of the discriminant function analysis for morphometric and meristic characters

\begin{tabular}{|c|c|c|c|c|c|c|c|c|c|c|c|c|c|c|c|c|}
\hline \multirow[b]{2}{*}{ Variables } & \multicolumn{4}{|c|}{ Trachurus mediterroneus } & \multicolumn{4}{|c|}{ Trachurus trachurus } & \multicolumn{4}{|c|}{ Trochurus picturatus } & \multicolumn{4}{|c|}{ Tum turler } \\
\hline & $\begin{array}{l}\text { Wilks } \\
\text { lamb }\end{array}$ & F-rem. & p-level & Toler. & $\begin{array}{l}\text { Wilks } \\
\text { lamb }\end{array}$ & F-rem. & p-level & Toler. & $\begin{array}{l}\text { Wilks } \\
\text { lamb }\end{array}$ & F-rem. & p-level & Toler. & $\begin{array}{l}\text { Wilks } \\
\text { lamb }\end{array}$ & F-rem. & p-level & Toler. \\
\hline \multicolumn{17}{|c|}{ Morphometric variables } \\
\hline $\mathrm{HL}$ & 0.065 & 2.462 & 0.023 & 0.899 & 0.078 & 1.102 & 0.370 & 0.252 & 0.490 & 0.804 & 0.379 & 0.670 & 0.001 & 47.55 & 0.000 & 0.657 \\
\hline $\mathrm{LL}$ & 0.058 & 1.435 & 0.202 & 0.875 & 0.097 & 3.553 & 0.015 & 0.474 & 0.592 & 5.768 & 0.024 & 0.625 & 0.002 & 93.04 & 0.000 & 0.840 \\
\hline D1L & 0.055 & 1.007 & 0.441 & 0.848 & 0.072 & 0.446 & 0.773 & 0.579 & 0.493 & 0.931 & 0.344 & 0.844 & 0.000 & 1.230 & 0.295 & 0.821 \\
\hline D2L & 0.052 & 0.614 & 0.761 & 0.902 & 0.073 & 0.519 & 0.721 & 0.792 & 0.477 & 0.151 & 0.700 & 0.661 & 0.001 & 6.443 & 0.002 & 0.855 \\
\hline $\operatorname{PrAL}$ & 0.051 & 0.476 & 0.867 & 0.834 & 0.087 & 2.341 & 0.074 & 0.327 & 0.474 & 0.005 & 0.940 & 0.516 & 0.002 & 122.7 & 0.000 & 0.740 \\
\hline $\mathrm{BD}$ & 0.080 & 4.619 & 0.000 & 0.770 & 0.090 & 2.700 & 0.046 & 0.252 & 0.476 & 0.116 & 0.736 & 0.649 & 0.001 & 8.002 & 0.000 & 0.786 \\
\hline $\mathrm{ED}$ & 0.103 & 7.913 & 0.000 & 0.925 & 0.100 & 3.880 & 0.000 & 0.284 & 0.481 & 0.344 & 0.563 & 0.594 & 0.001 & 10.03 & 0.000 & 0.615 \\
\hline $\mathrm{AL}$ & 0.053 & 0.694 & 0.695 & 0.874 & 0.072 & 0.383 & 0.818 & 0.792 & 0.507 & 1.626 & 0.214 & 0.823 & 0.000 & 3.023 & 0.051 & 0.852 \\
\hline PL & 0.059 & 1.632 & 0.136 & 0.835 & 0.094 & 3.129 & 0.026 & 0.822 & 0.487 & 0.671 & 0.420 & 0.660 & 0.001 & 12.40 & 0.000 & 0.935 \\
\hline CPD & 0.059 & 1.550 & 0.161 & 0.821 & 0.096 & 3.366 & 0.019 & 0.295 & 0.474 & 0.001 & 0.975 & 0.826 & 0.000 & 1.401 & 0.249 & 0.853 \\
\hline \multirow[t]{2}{*}{ ML } & 0.056 & 1.243 & 0.292 & 0.885 & 0.094 & 3.142 & 0.026 & 0.428 & 0.475 & 0.068 & 0.796 & 0.770 & 0.000 & 3.707 & 0.026 & 0.906 \\
\hline & & \multirow{2}{*}{\multicolumn{3}{|c|}{$F(88.370)=2.473$}} & & \multicolumn{3}{|c|}{$F(44.135)=3.115$} & & \multicolumn{3}{|c|}{$F(11.23)=2.320$} & & \multicolumn{3}{|c|}{$F(22.29)=418.25$} \\
\hline Total & 0.048 & & & & 0.069 & & & & 0.473 & & & & 0.0009 & & & \\
\hline \multicolumn{17}{|c|}{ Meristic variables } \\
\hline $\mathrm{P}$ & 0.638 & 1.753 & 0.086 & 0.995 & 0.287 & 0.726 & 0.578 & 0.953 & 0.875 & 0.142 & 0.725 & 0.658 & 0.074 & 1.251 & 0.287 & 0.996 \\
\hline D1 & 0.612 & 0.341 & 0.949 & 0.995 & 0.274 & 0.204 & 0.934 & 0.972 & 0.884 & 0.184 & 0.689 & 0.799 & 0.074 & 1.407 & 0.246 & 0.996 \\
\hline $\mathrm{D} 2$ & 0.681 & 4.00 & 0.000 & 0.988 & 0.383 & 4.740 & 0.000 & 0.870 & 0.937 & 0.437 & 0.544 & 0.504 & 0.093 & 45.06 & 0.000 & 0.921 \\
\hline A & 0.798 & 10.24 & 0.000 & 0.987 & 0.383 & 4.714 & 0.000 & 0.855 & 0.887 & 0.201 & 0.676 & 0.655 & 0.093 & 44.04 & 0.000 & 0.923 \\
\hline \multirow[t]{2}{*}{$\mathrm{L}$} & 0.634 & 1.53 & 0.146 & 0.997 & 0.305 & 1.491 & 0.220 & 0.966 & 0.847 & 0.008 & 0.930 & 0.881 & 0.570 & 1103.58 & 0.000 & 0.993 \\
\hline & & \multirow{2}{*}{\multicolumn{3}{|c|}{$F(40.112)=3.4215$}} & & \multirow{2}{*}{\multicolumn{3}{|c|}{$\mathrm{F}(20.150)=3.6342$}} & & \multirow{2}{*}{\multicolumn{3}{|c|}{$F(5.4)=0.1462$}} & \multicolumn{4}{|c|}{$F(10.65)=175.65$} \\
\hline Total & 0.605 & & & & 0.270 & & & & 0.845 & & & & 0.073 & & & \\
\hline
\end{tabular}


Table 2: Structure matrix of discriminant loadings for each of morphometric and meristic variable selected by the backward stepwise Discriminant Function

\begin{tabular}{|c|c|c|c|c|c|c|c|c|c|}
\hline \multirow[b]{2}{*}{ Variables } & \multicolumn{3}{|c|}{ Trachurus me diterroneus } & \multicolumn{3}{|c|}{ Trachurus trochurus } & \multirow{2}{*}{$\begin{array}{l}\text { Trachurus } \\
\text { picturatus } \\
\text { CV1 }\end{array}$} & \multicolumn{2}{|c|}{ All species } \\
\hline & CV1 & $\mathrm{CV} 2$ & CV3 & CV1 & $\mathrm{CV} 2$ & CV3 & & CV1 & $\mathrm{CV} 2$ \\
\hline \multicolumn{10}{|c|}{ Morphometric variables } \\
\hline $\mathrm{HL}$ & 0.4284 & 0.0709 & 0.5508 & -0.3063 & 0.4337 & -0.7811 & -0.3903 & 0.5951 & -0.5139 \\
\hline LL & 0.1299 & 0.3508 & -0.7081 & 0.7961 & 0.4456 & -0.0976 & -0.1214 & -0.5236 & 0.6439 \\
\hline D1L & -0.1936 & 0.0318 & 0.2585 & -0.1837 & 0.1706 & 0.4241 & -0.2960 & -0.0214 & -0.1430 \\
\hline D2L & -0.0856 & -0.3387 & 0.0434 & 0.1676 & -0.2725 & -0.0826 & 0.1373 & 0.1233 & 0.2879 \\
\hline PrAL & 0.0234 & 0.2131 & -0.0136 & 0.1846 & -1.0410 & 0.2195 & 0.0302 & 0.7651 & 0.5357 \\
\hline $\mathrm{BD}$ & 0.2937 & 0.9315 & 0.3209 & 0.8505 & -0.7153 & -0.6252 & -0.2172 & -0.2210 & -0.2843 \\
\hline $\mathrm{ED}$ & 0.7880 & -0.3234 & -0.2223 & 0.9202 & -0.4610 & 0.9701 & -0.7805 & 0.1939 & 0.4067 \\
\hline $\mathrm{AL}$ & 0.2343 & 0.0057 & -0.3842 & -0.2071 & -0.0817 & -0.2557 & -0.3095 & -0.2119 & 0.0548 \\
\hline PL & -0.2402 & -0.3782 & 0.4238 & -0.5087 & -0.3671 & 0.4276 & -0.2858 & -0.1531 & 0.3705 \\
\hline CPD & 0.2787 & -0.4488 & -0.2127 & 0.8291 & -0.8387 & -0.0079 & -0.0100 & -0.1504 & -0.0066 \\
\hline ML & 0.1238 & -0.5128 & -0.1498 & 0.0765 & 1.0365 & -0.2219 & 0.0853 & 0.1873 & -0.1410 \\
\hline Eigenval & 4.4230 & 0.9228 & 0.2869 & 3.7932 & 1.1076 & 0.3031 & 1.1097 & 36.4810 & 27.2012 \\
\hline Cum.prop & 0.7254 & 0.8768 & 0.9238 & 0.7157 & 0.9247 & 0.9819 & 1.0000 & 0.5728 & 1.0000 \\
\hline \multicolumn{10}{|c|}{ Meristic variables } \\
\hline $\mathrm{P}$ & -0.0512 & -0.0626 & 0.9582 & -0.2606 & -0.2901 & 0.0260 & -0.5808 & 0.0145 & -0.1492 \\
\hline D1 & 0.0367 & 0.0401 & 0.1789 & -0.0779 & 0.1113 & -0.4227 & -0.5979 & 0.0559 & -0.1315 \\
\hline D2 & 0.3037 & 0.8281 & -0.0723 & -0.5922 & -0.7270 & 0.4471 & -1.1235 & 0.0500 & -0.8340 \\
\hline A & -0.9827 & 0.1564 & -0.0363 & -0.6128 & 0.6813 & -0.5302 & 0.6875 & -0.1914 & 0.7686 \\
\hline $\mathrm{L}$ & 0.0335 & -0.4876 & -0.2663 & 0.1637 & -0.6733 & -0.6791 & 0.1254 & -0.9876 & -0.1650 \\
\hline Eigenval & 0.3330 & 0.1412 & 0.0572 & 1.8432 & 0.2543 & 0.0262 & 0.1828 & 8.0472 & 0.5015 \\
\hline Cum. Prop & 0.5971 & 0.8504 & 0.9529 & 0.8631 & 0.9822 & 0.9945 & 1.0000 & 0.9413 & 1.0000 \\
\hline
\end{tabular}
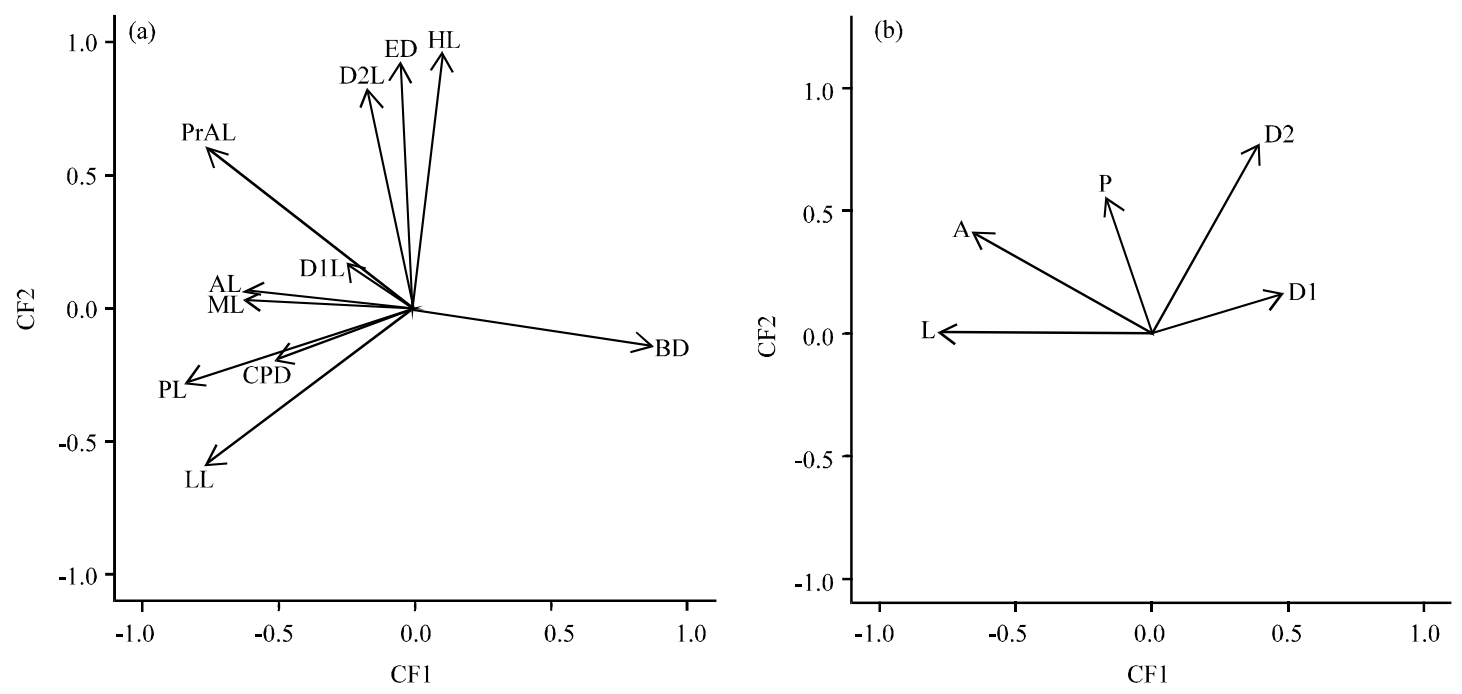

Fig. 3: Contribution of morphometric (a) and meristic (b) characters to the discriminant functions. Vectors indicate the loadings of the scores for each variable on the first and second discriminant functions

variables of the discriminant analysis (Table 2) which is useful for discriminating Trachurus species. There was good separation of $T$. trachurus from $T$. mediterraneus and $T$. picturatus along axis 1 and 2 .

Analyses of the meristic characters revealed notable significant differences between the three Trachurus species. Derived discriminant functions in DFA using 5 meristic characters identified LS as significant contributors while PFR, DFR1, DFR2 and AFR were not significant (Table 1). Wilk's lambda tests showed small differences among the three species when their meristic characters were compared with morphometrics. Moreover, the stepwise analysis revealed that only one meristic character contributed significantly to the multivariate discrimination of the three species of Trachurus (Table 2). Among the 5 characters that were found to be useful in population differentiation. In this case, the plot of the two first canonical variates (Fig. 3) which account for 94.13 and $5.87 \%$ of total variation (Table 2 ). The plots derived from both discriminant function analyses (Fig. 4) also 

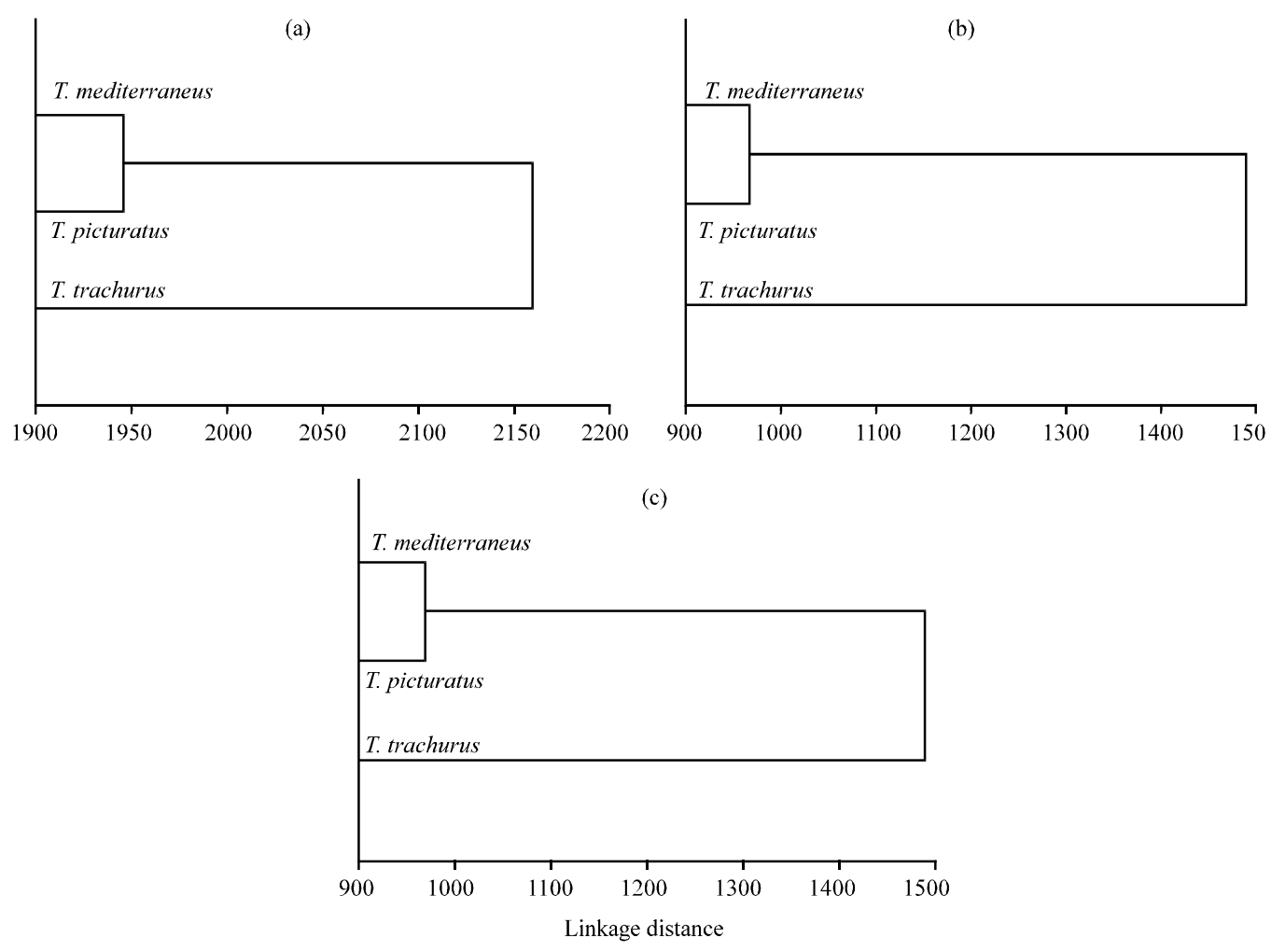

Fig. 4: UPGMA cluster analysis based on Mahalanobis $\mathrm{D}^{2}$ distances between the morphometric (a) meristic (b) and morphometric and meristic (c) characters

confirmed that morphometric characters are much more effective for discriminating between Trachurus species than meristic characters which is expressed lower distances among species. The dissimilarity between morphometric and meristic data showed that unlike meristic characters which are fixed early in life, morphometric characters typically show ontogenetic changes associated with allometric growth (Gould, 1966) and may be labile to environmental influences throughout life (Wainwright et al., 1991). Discriminant function analyses indicated that morphometric and meristic differentiation among species was largely due to differences in the head characters of fish which may reflect differential habitat use.

Multivariate analysis of both morphological and meristic characters has been used successfully on Trachurus species as a tool for separating species from same geographical regions. Especially, T. mediterraneus and T. trachurus share the same areas and have similar appearances which make identification on the species level rather difficult. T. trachurus is usually discriminated by the presence of smaller eye has little than 74 scales in the lateral line. The observed differences in morphometric characteristics of related Trachurus species have a genetic or environmental basis remains an important question. It is interesting to note that for several of the external morphometric characters which show significant variation, values for $T$. picturatus and for T. trachurus and T. mediterraneus tend to be at opposite extremes and standardized body depth is higher in T. trachurus and $T$. mediterraneus than in the deep seas form (T. picturatus). This could indicate the selective effect of interspecific competition, since it is only around the South Aegean sea and North-eastern Mediterranean sea that these three species overlap substantially in their range. Thus, T. picturatus tend to be more different from $T$. trachurus and T. mediterraneus.

To investigate the phenotypic relationships between the examined species a dendrogram was constructed based on Mahalanobis distances using UPGMA cluster analysis (Sneath and Sokal, 1973). For both morphometric and meristic characters, the dendrogram obtained by UPGMA cluster analysis was revealed 3 major groups containing $T$. mediterraneus, $T$. mediterraneus and T. picturatus populations from nine Turkish localities (Fig. 5). The results on species discrimination from the 

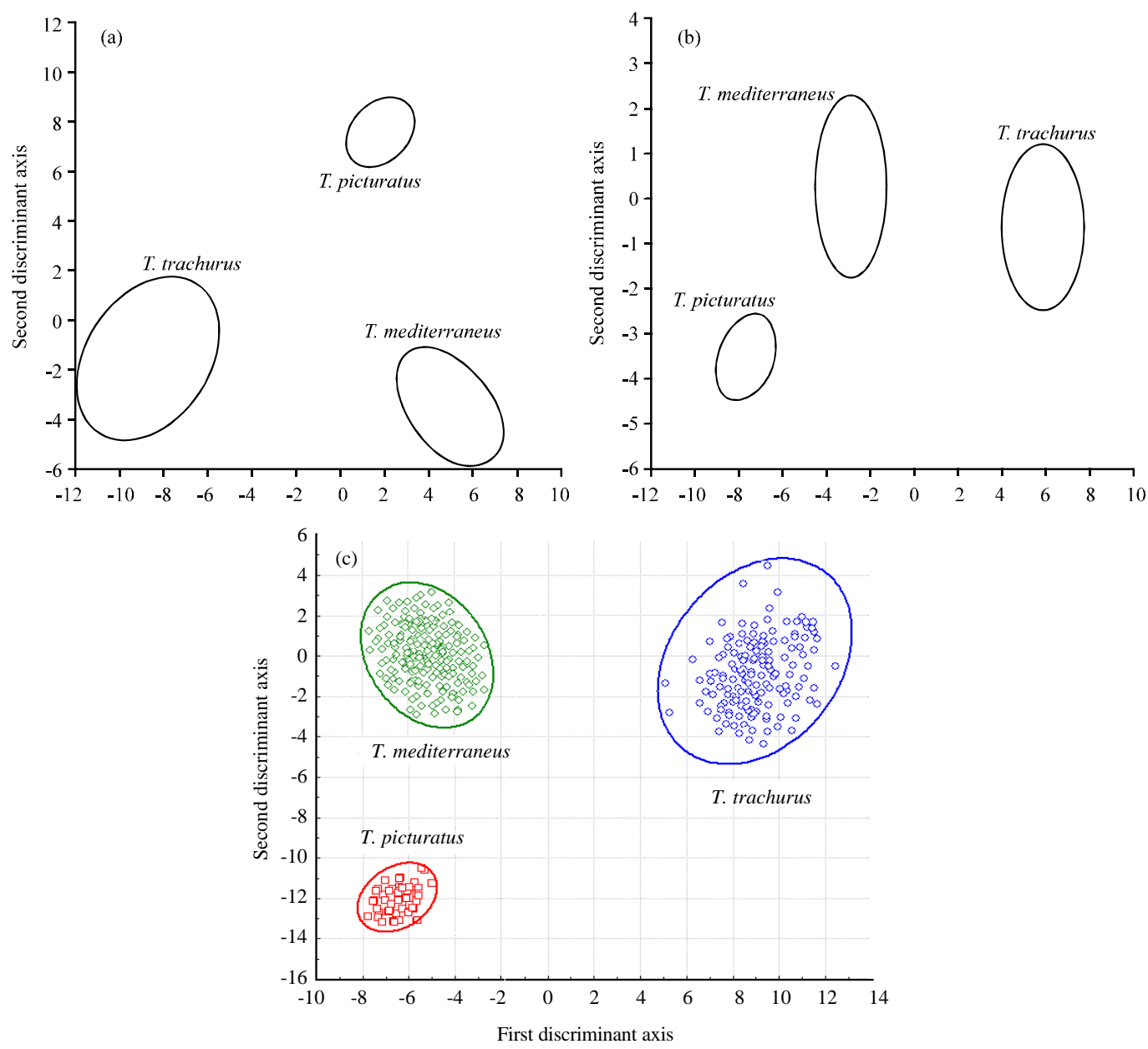

Fig. 5: Scatterplots of the Discriminant Function Analysis (DFA) scores along the first and second root for the nine collection sites of Trachurus species based on the morphometric (a) meristic (b) and morphometric and meristic characters (c) with $95 \%$ confidence ellipses

present study are consistent with results of genetic analysis by Karaiskou et al. (2003) and Bektas and Belduz (2008) who indicated that T. mediterraneus and $T$. picturatus are genetically more closely related to each other than either is to T. trachurus.

\section{CONCLUSION}

The discriminant function analysis revealed that this technique was sensitive enough to separate the three Trachurus species since, the plot (Fig. 5) showed a high convergence for the three species.

\section{ACKNOWLEDGEMENTS}

This research is partially supported by The Research Foundation of Karadeniz Technical University (KTU 2006.111.004.1)

\section{REFERENCES}

Bektas, Y. and A.O. Belduz, 2008. Molecular phylogeny of Turkish Trachurus species perciformes: Carangidae inferred from mitochondrial DNA analyses. J. Fish Biol., 73: 1228-1248.

Belduz, A.O. and Y. Bektas, 2009. Morphological variation among atlantic horse mackerel, Trachurus trachurus populations from Turkish coastal waters. J. Anim. Vet. Adv., 8: 511-517.

Boetius, J., 1980. Atlantic Anguilla. A presentation of old and new data of total numbers ofvertebrae with special reference to the occurrence of Anguilla rostrata in Europe. Dana, 1: 1-28.

Elliott, N.G., K. Haskard and J.A. Koslow, 1995. Morphometric analysis of orange roughy MHoplostethus atlanticus off the continental slope of Southern Australia. J. Fish Biol., 46: 202-220. 
Eschmeyer, W.N., 2003. Catalog of fishes. Updated database version of March 2003. Catalog Databases as Made Available to FishBase in March 2003. http://www. fishbase.org/.

Fridriksson, A., 1958. The tribes of North Coast herring of Iceland with special reference to the period 1948-1955. Rapports du Conseil pour l'Exploration de la Mer, 143: $36-44$.

Gould, S.J., 1966. Allometry and size in ontogeny and phylogeny. Biol. Rev., 41: 587-640.

Johnson, R.A. and D.W. Wichern, 1992. Applied Multivariate Statistical Analysis. 3rd Edn., PrenticeHall, New Jersey, pp: 642.

Karaiskou, N., A. Apostolidis, A. Triantafyllidis, A. Kouvatsi and C. Triantaphyllidis, 2003. Genetic identification and phylogeny of three species of the genus Trachurus Based on mitochondrial DNA analysis. Mar. Biotechnol., 5: 493-504.

Murta, A.G., 2000. Morphological variation of horse mackerel Trachurus trachurus in the Iberian and North African Atlantic: Implications for stock identification. ICES J. Mar. Sci., 57: 1240-1248.

Nichols, J.T., 1920. A key to the species of Trachurus. Bull. Am. Mus. Nat. Hist., 42: 477-481.
Pierce, G.J., L.C. Hastie, A. Guerra, R.S. Thorpe, F.G. Howard and P.R. Boyle, 1994. Morphometric variation in Loligo forbesi and Loligo vulgaris: Regional, seasonal, sex, maturity and worker differences. Fish. Res., 21: 127-148.

Santic, M., I. Jardas and A. Pallaora, 2002. Age, growth and mortality rate of horse mackerel, Trachurus trachurus (L.), living in the eastern central Adriatic. Period. Biol., 104: 165-173.

Sneath, P.H.A. andR.R. Sokal, 1973. Numerical Taxonomy. W.H. Freeman and Company, San Francisco, ISBN: 07167-0697-0.

Thorpe, R.S., 1976. Biometric analysis of geographic variation and racial affinities. Biol. Rev. Cambr. Phil. Soc., 51: 407-452.

Tudela, S., 1999. Morphological variability in a Mediterranean, genetically homogeneous population of the European anchovy, Engraulis encrasicolus. Fish. Res., 42: 229-243.

Turan, C., 2004. Stock identification of mediterranean horse mackerel (Trachurus mediterraneus) using morphometric and meristic characters. ICES J. Mar. Sci., 61: 774-781.

Wainwright, P.C., C.W. Rosenberg and G.G. Mittelbach, 1991. Trophic polymorphism in the pumpkinseed sunfish (Lepomis gibbosus L.): Effects of environment on ontogeny. Funct. Ecol., 5: 40-55. 